\title{
Development of Asymmetric Low Pressure Reverse Osmosis- Surfactants Membrane: Effect of Surfactant Types and Concentration
}

\author{
Nor Azirah Sulaiman², Abdul Rahman Hassan ${ }^{1,2 *}$, Sabariah Rozali², \\ Nurul Hannan Mohd Safari², Che Wan Insyirah Che Wan Takwa², \\ Al Dabbaas Khuzama Mansoor A², Muhammad Hafiz Md Saad² \\ 1 Faculty of Innovative Design and Technology, Sultan Zainal Abidin University, 21300 Kuala Nerus, Terengganu, Malaysia
2 East Coast Environmental Research Institute, Sultan Zainal Abidin University, 21300 Kuala Nerus, Terengganu, Malaysia
${ }^{*}$ Corresponding author, e-mail: rahmanhassan@unisza.edu.my
}

Received: 19 October 2018, Accepted: 27 February 2019, Published online: 21 May 2019

\begin{abstract}
The effect of surfactants that are cationic (Cetyl trimethylammonium bromide (CTAB)), anionic (Sodium Dodecyl Sulphate (SDS)) and non-ionic (Triton X-100) on performance, morphologies and molecular orientation of Polysulfone (PSF) low pressure reverse osmosis (LPRO) membrane were addressed. The experimental data showed that the increasing of $0.5 \mathrm{wt} \%$ in surfactant concentration produced higher pure water permeation (PWP) and flux. At $2.5 \mathrm{wt} \%$ of SDS, the LPRO membranes achieved the highest PWP of about $64.42 \mathrm{~L} / \mathrm{m}^{2} \times \mathrm{h}$ while $3.0 \mathrm{wt} \%$ of CTAB demonstrated the highest flux of $55.28 \mathrm{~L} / \mathrm{m}^{2} \times \mathrm{h}$. Analysis from morphological results found that the optimal performance at $89.6 \%$ rejection was produced by the membrane with $2 \mathrm{wt} \%$ SDS which is a good promoter for the fine morphological structures of the membrane, thus producing fine spectrum of molecular orientation factor.
\end{abstract}

Keywords

reverse osmosis, surfactant, morphology, molecular orientation, desalination

\section{Introduction}

Asymmetric membranes are used for ultrafiltration, gas separation and reverse osmosis processes because of their high selectivity, permeability and mechanical strength in high pressure application. Phase inversion via immersion precipitation process was the main technique used to prepare these membranes [1]. In the formation process, two or more components involved the conversion of homogenous polymer solution to a two-phase system (the solid polymer rich phase and the liquid polymer poor phase) [2]. The succeeding solidification process of the phase separated solution give a porous and asymmetric structure [3].

In this research study, polymer material of polysulfone (PSF) had been used to produce low pressure reverse osmosis (LPRO) surfactant membrane. PSF is a polymer widely used as a material for liquid separation processes as it has excellent characteristics which include good solubility in solvents, high thermal resistances, high mechanical resistances of the films, and also improve water stability [4-6].

Introducing of an additive in the membrane forming system provide an effective alternative in controlling the membrane formation process. PVP is a well-known polymeric additive that can increase the viscosity of the polymer solution. This pore-forming agent can influence macrovoids formation and increase permeability of the membrane [7]. Research on the effect of PVP have been studied and the results indicated that, concentration of PVP between $0 \mathrm{wt} \%$ to $3 \mathrm{wt} \%$ in the membrane system, increased the macrovoids formation instead of using the concentration from $3 \mathrm{wt} \%$ to $6 \mathrm{wt} \%$ which suppressed the macrovoids [8]. Zuo et al. [9] also reported the similar finding of PVP concentration on structure and performance of composite scaffold. The results suggested that small amount of PVP enhanced the porosity and excess PVP would suppressed the formation of pores.

Addition of surfactant as one of the materials necessary for membrane making formulation can be one of the effective strategies to produce high performance membrane with high selectivity. The effects of surfactants as additive in the process of membrane fabrication were reported in other studies. Sodium dodecyl sulphate (SDS) as anionic 
surfactant was added as additive into polysulfone (PSF) and polyvinylidene fluoride (PVDF) membrane formulation for brackish-seawater desalination and protein rejection as reported by Ali et al. [10] and Fadilah et al. [11], respectively.

Fadilah et al. [12] studied that the miscibility between addition of appropriate surfactant and coagulant plays an important role in the suppressed or induced formation process of various sizes of pores (macrovoids and finger-like pores) in the sub-layer. High miscibility of surfactants with coagulants may be able to extend the formation of finger-like pores and macrovoids. Obviously, large pores are formed in the sub-layer of the membrane.

Ghaemi et al. [13] had reported on addition of SDS which resulted thinner skin-layer in the membrane that give higher pure water flux, superior rejection and flux compared to cellulose acetate (CA) membrane without surfactant. Zainal et al. [14] also observed that SDS makes the membrane structure more porous in terms of formation of larger macrovoids. Besides, microvoids also contains in the support layer of membranes, which can leads to the lower mechanical strength of the membrane.

The effects of temperature and concentration of cationic surfactant, which is cetyl trimethylammonium bromide (CTAB) in the formation of asymmetric nanofiltration membrane is reported by Mulijani et al. [15]. The result indicated that the formation of membrane pore increases as the addition of CTAB increases. Saedi et al. [16] demonstrated that the addition of surfactants (SDS, CTAB and Triton X-100) on structure and performance of PES membrane increases the formation of macrovoids and large finger-like pores in the sub-layer of membranes.

Fadilah et al. [12] investigated that the water flux variation can be explained as the incorporation of combination anionic with non-ionic surfactants enhanced the hydrophilicity of the membrane which improves the water permeation to a certain extent. Thus, the experimental analysis of the combination of both non-ionic surfactants resulted in high hydrophilicity compared to the membranes without surfactant.

Therefore, the aim of this study is to investigate the influence of surfactant types (cationic, anionic and nonionic) and concentration on performance, morphology and molecular properties of LPRO membranes which are very important towards better understanding in the correlation between the materials, fabrication parameters and properties of final membranes for different applications.

\section{Materials and methods}

\subsection{Materials}

Polysulfone (PSF (Udel-P1700)) supplied by Solvay was used as polymer, while N-methyl-2-pyrrolidone (NMP, $>99 \%$ ) from Merck was used as solvent. The additive, Polyvinylpyrrolidone (PVP, K29-32) was supplied by Acros Organics utilized as an additive in in the membrane formulation. Cetyl trimethylammonium bromide (CTAB) supplied by EMD Chemicals, Sodium Dodecyl Sulphate (SDS) and Triton X-100 supplied by Fisher Scientific UK were used as surfactant. Ethanol and n-hexane that used for pre-treatment step were supplied by Merck. Sodium chloride, $\mathrm{NaCl}$ supplied by Merck was used as the solute for the desalination test.

\subsection{Membranes preparation}

Homogeneous membrane formulation as shown in Table 1 comprises of PSF/NMP/PVP and different surfactant which are CTAB (cationic), SDS (anionic) and Triton X-100 (nonionic) was stirred up to 8 hours at $50{ }^{\circ} \mathrm{C}$ to $60^{\circ} \mathrm{C}$. The solution was poured and cast on glass plate using casting knife with the thickness of about $150 \mu \mathrm{m}$. For immersion precipitation process, the membrane was immersed into water. In order to ensure complete phase separation, the membrane was immersed in water for 1 day. Then, the membrane was immersed in ethanol for 1 day and n-hexane for 3 hours to ensure all the solvents is completely removed.

Table 1 Composition of PSF-Surfactants LPRO membranes

\begin{tabular}{cccccc}
\hline $\begin{array}{c}\text { PSF } \\
(\mathbf{w t} \%)\end{array}$ & $\begin{array}{c}\text { NMP } \\
(\mathbf{w t} \%)\end{array}$ & $\begin{array}{c}\text { PVP } \\
(\mathbf{w t} \%)\end{array}$ & CTAB & SDS & $\begin{array}{c}\text { Triton } \\
\text { X-100 }\end{array}$ \\
\hline 21 & 76.0 & 3.0 & 0 & 0 & 0 \\
21 & 75.0 & 3.0 & 1.0 & 0 & 0 \\
21 & 74.5 & 3.0 & 1.5 & 0 & 0 \\
21 & 74.0 & 3.0 & 2.0 & 0 & 0 \\
21 & 73.5 & 3.0 & 2.5 & 0 & 0 \\
21 & 73.0 & 3.0 & 3.0 & 0 & 0 \\
21 & 75.0 & 3.0 & 0 & 1.0 & 0 \\
21 & 74.5 & 3.0 & 0 & 1.5 & 0 \\
21 & 74.0 & 3.0 & 0 & 2.0 & 0 \\
21 & 73.5 & 3.0 & 0 & 2.5 & 0 \\
21 & 73.0 & 3.0 & 0 & 3.0 & 0 \\
21 & 75.0 & 3.0 & 0 & 0 & 1.0 \\
21 & 74.5 & 3.0 & 0 & 0 & 1.5 \\
21 & 74.0 & 3.0 & 0 & 0 & 2.0 \\
21 & 73.5 & 3.0 & 0 & 0 & 2.5 \\
21 & 73.0 & 3.0 & 0 & 0 & 3.0 \\
\hline & & & & & 0 \\
\hline
\end{tabular}


These processes were carried out at room temperature. As the final stage, the membrane was dried for at least 1 day.

\subsection{Reverse osmosis performance evaluation}

Reverse osmosis performance in terms of pure water permeation (PWP), seawater flux and salt rejection for the LPRO membranes were tested using the well-known Millipore filtration cell (lab-scale dead end filtration apparatus) with circular filtration cell having an effective area of $1.38 \times 10^{-3} \mathrm{~m}^{2}$. To begin with, the circular membrane coupons loaded in the filtration cells were pressured at $500 \mathrm{kPa}$ with deionized water at least $30 \mathrm{~min}$ for compaction before the actual performance is carried out. Desalination tests were then carried out at $500 \mathrm{kPa}$ of operating pressure with aqueous solution containing 30000 ppm represent seawater. The PWP was determined by measuring the permeate volume collected over a certain period in terms of liter per square meter per hour $\left(\mathrm{L} / \mathrm{m}^{2} \times \mathrm{h}\right)$ and calculated through the following Eq. (1):

$J_{w}=\frac{Q}{A \times t}$

where $J_{w}$ is the volumetric PWP, $A$ is the effective area of the membrane for permeation, and $Q$ is the volume of permeation over a time interval, $t$. The permeate flux was calculated using Eq. (2), whereas the salt rejection was evaluated using Eq. (3).

$J_{v}=\frac{v}{A \times t}$

where $J_{v}$ is the permeate flux of solution or pure water flux $\left(\mathrm{L} / \mathrm{m}^{2} \times \mathrm{h}\right), A$ is the effective area of membrane $\left(\mathrm{m}^{2}\right), t$ is the time (h) and $v$ is the volume of permeate solution collected (L).

$R=\left(1-\frac{C_{p}}{C_{f}}\right) \times 100$.

In which, $R$ is the removal (\%), $C_{p}$ and $C_{f}$ are the salt concentration in permeate and feed, respectively. The salt concentration was determined by measuring the electrical conductivity of the salt solution using a conductivity meter (SensION EC5, HACH Instrument).

\subsection{Membranes morphologies}

The cross-sectional images of the prepared membranes was investigated by JSM-6360LA analytical scanning electron microscopes (SEM) (Tokyo, Japan). The membranes were immersed and fractured in liquid nitrogen, then sputter-coated with gold.

\subsection{Molecular orientation analysis}

The orientation of molecules in RO membrane samples were examined by transmission Variance 3100 Fouriertransform infrared (FTIR) Excalibur series. The analysis was done to study the functional group of the membrane. The sample was mounted into the sample holder with 'skin layer' facing the infrared (IR) beam. The spectra were recorded with cumulating 32 scans in total within the wave number of $4000-400 \mathrm{~cm}^{-1}$.

\section{Results and discussion}

In order to provide a better understanding for each membrane, the effect of surfactants on membranes performance was described separately. This is important to demonstrate that, with using different types and varies concentration of surfactants additives, they might played an important role and affected the performance for all membranes. The first set of data demonstrated the effect of surfactants on the performance while the second and third discussed of the morphologies and molecular orientations. The experimental data then was analyzed for verification of optimum concentration of surfactants for LPRO membrane performance.

\subsection{Effect of surfactants on performance of LPRO membranes}

\subsubsection{Cationic surfactant}

CTAB was selected for studying the effect of cationic surfactant on the performance of LPRO membranes. Fig. 1 (a) exhibits the effect of addition of CTAB in the casting solution on PWP while the effect of CTAB concentration on seawater flux and salt rejection of membrane prepared from PSF/NMP/PVP/CTAB system is shown in Fig. 1 (b).

Presence of CTAB in Fig. 1 (a) in the membrane formulation increases PWP which give the maximum value of $34.64 \mathrm{~L} / \mathrm{m}^{2} \times \mathrm{h}$ at $1 \mathrm{wt} \%$ CTAB. However, by increasing CTAB concentration more than $1 \mathrm{wt} \%$ resulted in decreasing of PWP. This might due to the high viscosity of casting solution that prevents the penetration of non-solvent and weaken the larger macrovoids and finger-like formation, hence lead to low permeability of membrane.

CTAB enhanced the hydrophilicity of membranes which leads to the increasing of membrane permeation [17]. Fig. 1 (b) showed the increasing of seawater flux as CTAB surfactant increased in the casting solution, and reaches the maximum volume of flux $\left(55.28 \mathrm{~L} / \mathrm{m}^{2} \times \mathrm{h}\right)$ at $3.0 \mathrm{wt} \%$. Meanwhile, the salt rejection of the membrane improves from $80.95 \%$ (without surfactant) up to $89.05 \%$ 

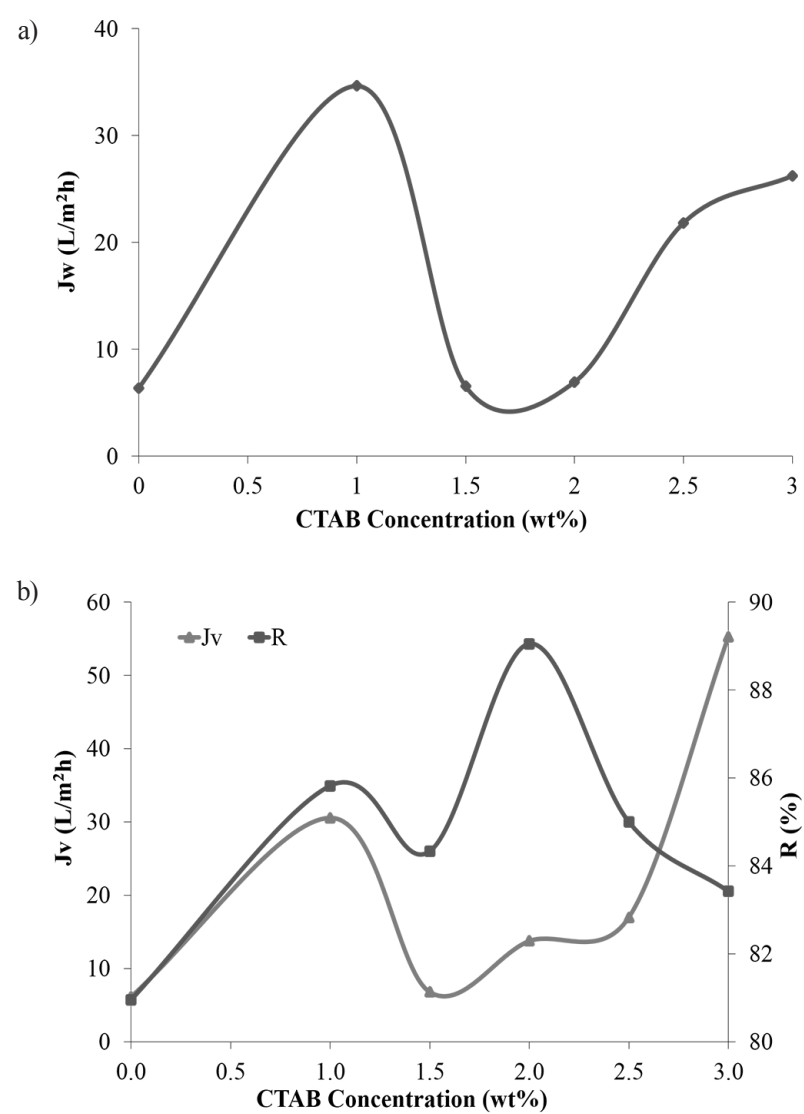

Fig. 1 Effect of CTAB concentration on (a) pure water permeation (b) seawater flux and salt rejection

(Flux, $13.75 \mathrm{~L} / \mathrm{m}^{2} \times \mathrm{h}$ ) in the presence of $2 \mathrm{wt} \%$ of CTAB. This finding fairly agreed according to Hassan et al. [18] which explained that addition of CTAB in dope formulation demonstrated lower flux and high rejection of dyes. By increasing CTAB concentration more than $2 \mathrm{wt} \%$, the salt rejection is gradually decreases up to $4.5 \%$. This phenomenon might be due to the formation of thick skin layer and fewer pores that resulting in lower rejection.

\subsubsection{Anionic surfactant}

To investigate the effect of anionic surfactant as additive, SDS was selected as strong anionic surfactant. Fig. 2 (a) shows the effect of SDS concentration on PWP for the prepared membrane. The result show that the PWP increases as SDS presence in the casting solution, and reaches the maximum value for the concentration at $2.5 \mathrm{wt} \%$ which is $60.42 \mathrm{~L} / \mathrm{m}^{2} \times \mathrm{h}$, then decreases afterwards. This is related to the previous study by Saedi et al. [16] which reported with the increasing amount of surfactant resulted in higher solution viscosity that prevents the penetration of non-solvent, and weaken macrovoid formation which decreases membrane porosity and permeability.
Fig. 2 (b) demonstrated the effect of SDS on seawater flux and salt rejection. The seawater flux improves from $6.14 \mathrm{~L} / \mathrm{m}^{2} \times \mathrm{h}$ (without the addition of SDS) up to $27.64 \mathrm{~L} / \mathrm{m}^{2} \times \mathrm{h}$ in the presence of $3 \mathrm{wt} \%$ of SDS in the casting solution. On the other hand, for salt rejection, it achieves the highest value at $2 \mathrm{wt} \%$ of SDS which is $89.6 \%$, and then decreases afterwards. Higher rejection rate may be due to the lower precipitation of solute particles solved in the water on the surface of the membrane [19]. The rejection of salt above $2 \mathrm{wt} \%$ has reduction of about $7.4 \%$ to $10.2 \%$. The rejection reduction may be due to the higher concentration of hydrophilic surfactant interfered with the interfacial polymerization which deteriorate the selective layer of the membrane.

\subsubsection{Non-ionic surfactant}

Triton X-100 was used as non-ionic surfactant in the casting solution. The effect of Triton X-100 concentration on PWP of LPRO membrane is depicted in Fig. 3 (a). By introducing $1 \mathrm{wt} \%$ of Triton $\mathrm{X}-100$, the PWP reaches the maximum volume which is $32.48 \mathrm{~L} / \mathrm{m}^{2} \times \mathrm{h}$. Increasing Triton $\mathrm{X}-100$ concentration more than $1 \mathrm{wt} \%$ resulted in declination of about $81.3 \%$ which gave value of $6.06 \mathrm{~L} / \mathrm{m}^{2} \mathrm{~h}$.

a)
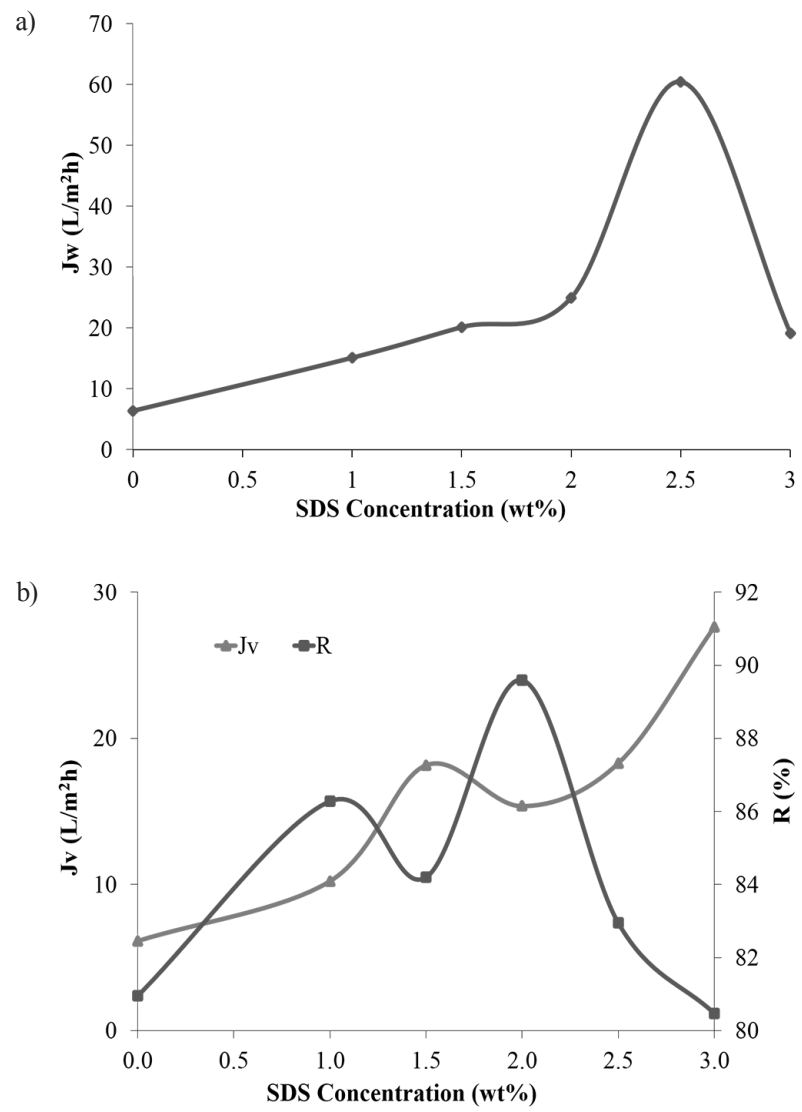

Fig. 2 Effect of SDS concentration on (a) pure water permeation (b) seawater flux and salt rejection 
Fig. 3 (b) shows the effect of Triton X-100 concentration on seawater flux and salt rejection of LPRO membrane. Variation of concentration plays an important role in determining the performance of the membrane [20]. The seawater flux decreases drastically as Triton X-100 was added to the casting solution which is from $6.14 \mathrm{~L} / \mathrm{m}^{2} \times \mathrm{h}$ to $2.69 \mathrm{~L} / \mathrm{m}^{2} \times \mathrm{h}$, and then it increases up to $6.1 \mathrm{~L} / \mathrm{m}^{2} \times \mathrm{h}$ at $3 \mathrm{wt} \%$. Membrane with lower permeability tend to have a declination in surface porosity and increasing in thickness of skin layer [21]. Meanwhile for the salt rejection, it shows that the salt performance is increase as the concentration of Triton X-100 increases, and then at $2.0 \mathrm{wt} \%$ of Triton X-100, the membranes achieved the optimum separation performance of about $85.57 \%$. Then, the rejection rate has declination of about $9.9 \%$ to $10 \%$.

Addition of surfactant in the dope formulation often increases and less often decreases the water flux. Both of this occurrence are agreeable with what was demonstrated by several researchers for similar system using water as non-solvent [22].

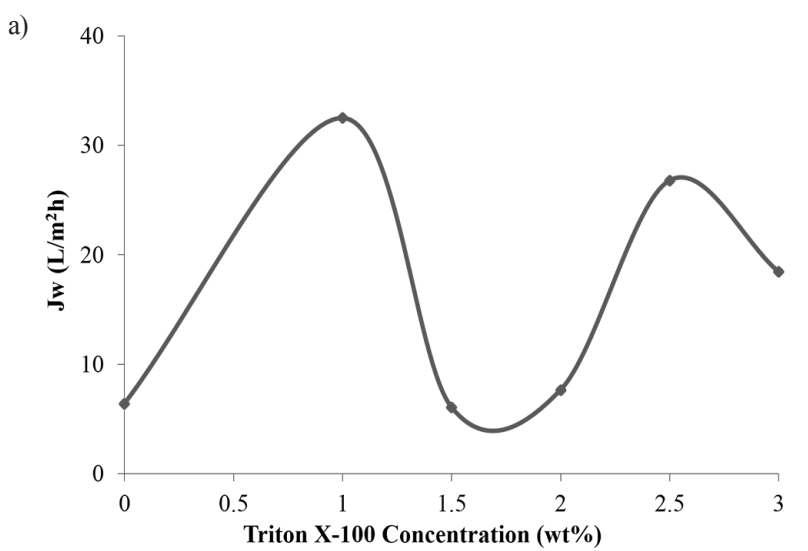

b)

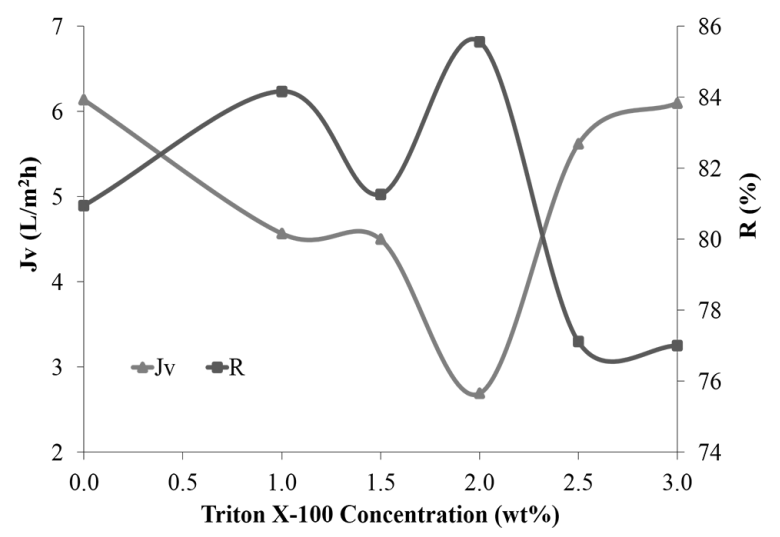

Fig. 3 Effect of Triton X-100 concentration on (a) pure water permeation (b) seawater flux and salt rejection

\subsubsection{Optimal characteristics of LPRO-surfactant membranes}

The data collected in the previous results are aligned with other finding that surfactants additive significantly affected the permeability, properties and morphology structure of the membrane [23]. Fig. 4 depicted the salt rejection with different types of surfactants used in blending polymer of PSF with PVP additive. This results suggested that addition of surfactants in a small amount between $0 \mathrm{wt} \%$ to $2 \mathrm{wt} \%$ was a proper emulsifier-agent that significantly improved the porosity, thus, resulting in higher permeability and rejection of PSF-surfactants membrane. Meanwhile, when further increased above $2 \mathrm{wt} \%$, it shows a declination of performance in which might be due to the suppression of the growth of pores. Overall, from the result and discussion of performance for all surfactants types, the concentration of $2 \mathrm{wt} \%$ were selected as the optimal membranes performances as it showed the maximum rejection of salt at $89.05 \%, 89.6 \%$ and $85.57 \%$ for CTAB, SDS and Triton X-100, respectively. High separation of salt indicates that the aim of producing highly selective asymmetric LPRO membranes was achieved. Thus in Fig. 4, it can be seen that SDS as an anionic surfactant was a best surfactant agent and enhancer for membrane permeability as it show the best performance of salt rejection among of the other membranes.

\subsection{Effect of surfactants on morphology of LPRO membranes}

SEM cross-sectional images of RO membranes with different surfactants at $2 \mathrm{wt} \%$ optimum concentration of performance are shown in Fig. 5 (a)-(d). Fig. 5 (a) exhibits a characteristic morphology of asymmetric RO membrane without addition of surfactant in the casting solution

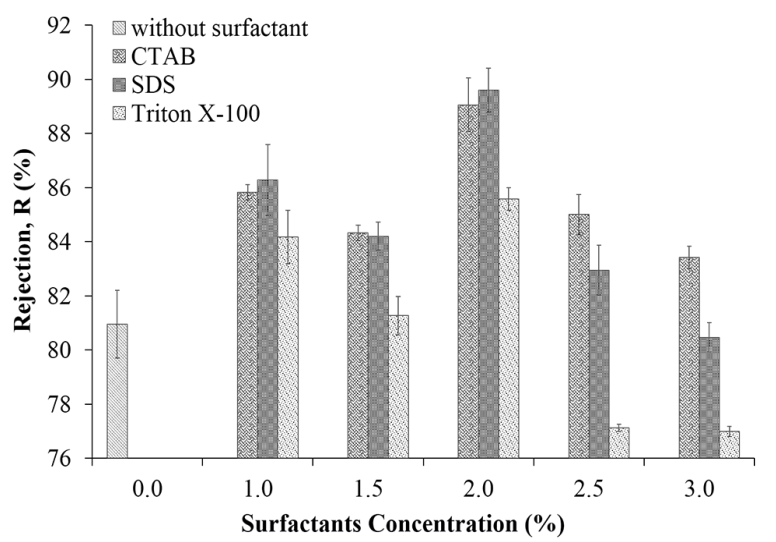

Fig. 4 Salt rejection of membranes without surfactant, with CTAB, with SDS and with Triton X-100 
which consist of a dense top layer and porous sub-layer. Formation of polymer-surfactant complex decreases the degree of polymer chain entanglement, therefore the penetration of non-solvent into the chain spaces can be increased and formation of macro-voids enhanced [16].

Then, $2 \mathrm{wt} \%$ of CTAB concentration from Fig. 5 (b) shows large macrovoids appeared and membrane porosity increased. It also can be observed that the thickness of the skin layer is lowered as compared to membrane without surfactant. The macrovoids seemed to be closed pore structure and did not inter-connect with other pores. The large size of macrovoids enhances the permeability performance of the membrane, which give the highest value of PWP and flux. The existence of spongy structures at the bottom of the sub-layer is a good characteristic, providing better rejection and resistance [24]. The spongy structures in Fig. 5 (b) was diminished. Thus, increased the porosity of membrane support layer and results in higher salt performance (Flux, $13.75 \mathrm{~L} / \mathrm{m}^{2} \times \mathrm{h}$; Rejection, $89.05 \%$ ). Therefore, the experimental data of SEM image was found to be in line with the previous result in Section 3.1.1.

Meanwhile, based on Fig. 5 (c), it is indicated that the addition of SDS in the casting solution causes an increase in the formation of macrovoids and number of pores compared with other membranes. Therefore, the higher rejection $(89.60 \%)$ and permeability $\left(15.37 \mathrm{~L} / \mathrm{m}^{2} \times \mathrm{h}\right)$ in the performance section might relate to the morphology of the membrane prepared with SDS surfactant. The high porosity of sub-layer of membranes prepared with SDS can leads to high performances of membranes [25, 26]. At $2 \mathrm{wt} \%$ SDS concentration, the membrane exhibited of asymmetrical features of dense top layer and porous sublayer as well as formation of larger macrovoids and finger-like structure compared with other membranes.

Besides, the thickness of the skin layer for Triton X-100 decreases in comparison to the SEM image of membrane without surfactant. Moreover, the porosity of the spongy structure of the sub-layer increases as well. Based on Fig. 5 (d), the membrane consist of dense top layer and porous sub layer structure. The formation of finger-like pores in the sub layer is fully developed. These structure of the membrane justify the analysis data presented in the previous result of permeate flux $\left(2.69 \mathrm{~L} / \mathrm{m}^{2} \times \mathrm{h}\right)$ and rejection (85.57\%). Triton X-100 contains linear alkyl ether chains. Thus, due to the formation of the polymer-surfactant complex, the repulsion between polymer chains is increased resulting in an increase in the free volume and as a result, the higher porosity of the membrane produced [16].
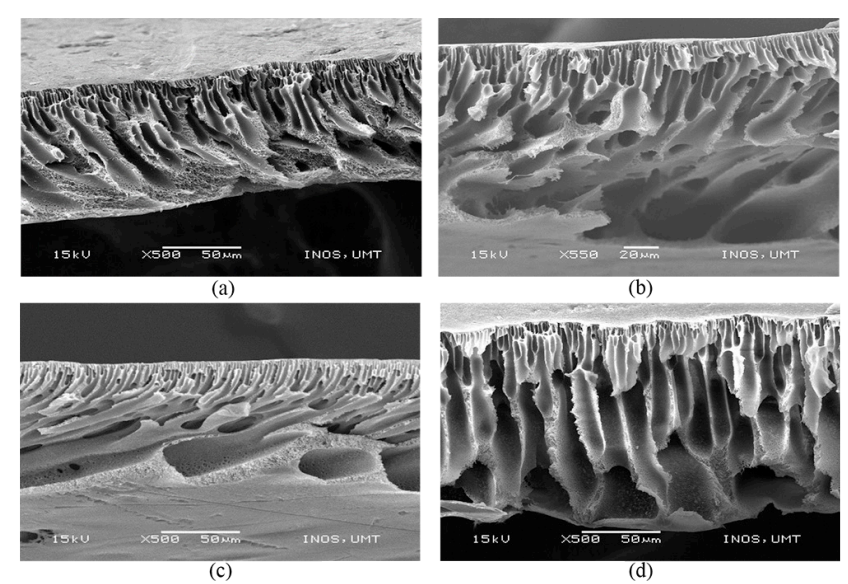

Fig. 5 SEM cross-sectional images of LPRO membranes prepared (a) without surfactant (b) with $2 \mathrm{wt} \%$ of CTAB (c) with $2 \mathrm{wt} \%$ of SDS (d) with $2 \mathrm{wt} \%$ of Triton X-100

Overall, analysis of morphology structures can be relates to the performance result of the prepared membranes.

\subsection{Effect of surfactants on molecular orientation of LPRO membranes}

Fig. 6 exhibits the FTIR spectrum of membrane without surfactant and membrane with surfactant of CTAB, SDS and Triton X-100 at optimum performance of desalination, respectively. FTIR plays a decisive role in order to study the intermolecular interaction between the molecules in the membrane. Based on the figure, it seems to have similar transmittance bands spectrum due to the similar basic structure of polymer (PSF) and additive (PVP).

The presence of PSF polymer in membrane without surfactant was observed near transmittance band at $1585 \mathrm{~cm}^{-1}$ $\left(\mathrm{C}=\mathrm{C}\right.$ bonds), $1243 \mathrm{~cm}^{-1}(\mathrm{C}=\mathrm{O}$ bond $)$ and $1151 \mathrm{~cm}^{-1}(\mathrm{~S}=\mathrm{O}$ bonds). These result were in line with the research by Karimi et al. [27]. In addition, the transmittance band observed at $1490 \mathrm{~cm}^{-1}$ owing to the $\mathrm{C}-\mathrm{N}$ bond stretching

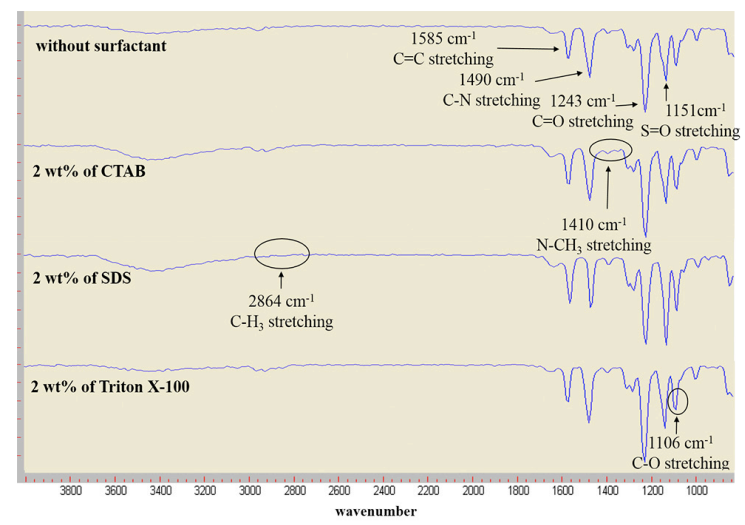

Fig. 6 FTIR spectrum for membrane without surfactant and with $2 \mathrm{wt} \%$ of CTAB, SDS and Triton X-100 
vibration proved that the presence of PVP additive molecule in the analyze membrane.

The addition of CTAB does not affect those functional group as they exhibit the same wavenumber as found in Fig. 6. Instead, the new $\mathrm{N}-\mathrm{CH}_{3}$ stretching transmittance band observed at $1410 \mathrm{~cm}^{-1}$ reveal the presence of CTAB in the membrane formulation. This is correspond to the study by Viana et al. [28] which reported that the peak at $1480 \mathrm{~cm}^{-1}$ was assigned to the $\mathrm{N}-\mathrm{CH}_{3}$ stretching of CTAB.

On the other hand, no significant peak observed for SDS membrane as displayed. Nevertheless, an absorption band of $\mathrm{C}-\mathrm{H}_{3}$ stretching bond at $2864 \mathrm{~cm}^{-1}$ appeared confirmed that the existence of SDS molecule in the membrane solution. This stretching bond value can be relate with the previous finding which discover the stretching of $\mathrm{C}-\mathrm{H}_{3}$ group from SDS at $2873 \mathrm{~cm}^{-1}$ [28].

The changes in the spectrum of the prepared membranes using different surfactants correspond to the improvement of the performance and permeability of the membranes [26]. The transmittance band for Triton X-100 membrane observed near $1106 \mathrm{~cm}^{-1}$ which assigned to the $\mathrm{C}-\mathrm{O}$ stretching, revealed the presence of the surfactant in the membrane solution. This peak agrees with the finding of Dumbrava et al. [29] which found the C-O stretching of Triton X-100 at $1016 \mathrm{~cm}^{-1}$ and $1022 \mathrm{~cm}^{-1}$.

\section{Conclusion}

From the study, an investigation on the influence of surfactants types and concentration on performance

\section{References}

[1] Zuo, D-Y., Xu, Y-Y., Xu, W-L., Zou, H-T. "The influence of PEG molecular weight on morphologies and properties of PVDF asymmetric membranes", Chinese Journal of Polymer Science, 26(04), pp. 405-414, 2008.

https://doi.org/10.1142/S0256767908003072

[2] Ma, Y., Shi, F., Ma, J., Wu, M., Zhang, J., Gao, C. "Effect of PEG additive on the morphology and performance of polysulfone ultrafiltration membranes", Desalination, 272(1-3), pp. 51-58, 2011. https://doi.org/10.1016/j.desal.2010.12.054

[3] Rahimpour, A., Madaeni, S. S., Mansourpanah, Y. "The effect of anionic, non-ionic and cationic surfactants on morphology and performance of polyethersulfone ultrafiltration membranes for milk concentration", Journal of Membrane Science, 296(1-2), pp. 110-121, 2007.

https://doi.org/10.1016/j.memsci.2007.03.029

[4] Voicu, S. I., Aldea, F., Radut, M., Nechifor, G. "Nanostructured polysulfone composite membranes", University Politehnica of Bucharest Scientific Bulletin Series B, 70(3), pp. 39-46, 2008. [online] Available at: https://www.scientificbulletin.upb.ro/rev_ docs_arhiva/full95792.pdf [Accessed: 05 January 2019] (permeability and rejection) was investigated and characterization (SEM and FTIR) were applied to study the morphological structure and molecular properties of the optimal LPRO membranes. This study has demonstrated that the addition of surfactants in the casting solution increases the formation of macrovoids and large finger-like pores in the sub-layer of RO membranes. This enhances the permeability and rejection of the membranes. The finding discovered that membranes with presence of CTAB, SDS and Triton X-100 at optimal concentration of $2 \mathrm{wt} \%$ achieved the separation performance about $89.05 \%, 89.6 \%$ and $85.57 \%$, respectively. In addition, the performance of the prepared membranes led towards fine formation of membrane pores with good separation capability and also promoting the fine spectrum of the molecular orientation. Therefore, this research proved that the surfactant materials and variation of concentration were very important towards membrane performance and properties for better understanding in improvement of membrane fabrication.

\section{Acknowledgement}

The authors wish to express their gratitude to the Faculty of Innovative Design and Technlogy, East Coast Environmental Research Institute (ESERI) of Universiti Sultan Zainal Abidin (UniSZA) for facilities and support to make this project success. This research did not receive any specific grant from funding agencies in the public, commercial, or not-for-profit sectors.

[5] Jee, K. Y., Kim, J. S., Kim, J., Lee, Y. T. "Effect of hydrophilic Cu3 (BTC) 2 additives on the performance of PVDF membranes for water flux improvement", Desalination and Water Treatment, 57(38), pp. 17637-17645, 2016.

https://doi.org/10.1080/19443994.2015.1085912

[6] Park, H. M., Jee, K. Y., Lee, Y. T. "Preparation and characterization of a thin-film composite reverse osmosis membrane using a polysulfone membrane including metal-organic frameworks", Journal of Membrane Science, 541, pp. 510-518, 2017.

https://doi.org/10.1016/j.memsci.2017.07.034

[7] Aroon, M. A., Ismail, A. F., Montazer-Rahmati, M. M., Matsuura, T. "Morphology and permeation properties of polysulfone membranes for gas separation: Effects of non-solvent additives and co-solvent", Separation and Purification Technology, 72(2), pp. 194-202, 2010.

https://doi.org/10.1016/j.seppur.2010.02.009

[8] Saljoughi, E., Mohammadi, T. "Cellulose acetate (CA)/ polyvinylpyrrolidone (PVP) blend asymmetric membranes: Preparation, morphology and performance", Desalination, 249(2), pp. 850-854, 2009.

https://doi.org/10.1016/j.desal.2008.12.066 
[9] Zuo, D. Y., Yan-Wang, Xu, W. L., Liu, H. T. "Effects of Polyvinylpyrrolidone on Structure and Performance of Composite Scaffold of Chitosan Superfine Powder and Polyurethane", Advances in Polymer Technology, 31(4), pp. 310-318, 2011. https://doi.org/10.1002/adv.20254

[10] Ali, N. S. M., Hassan, A. R., Yunus, R. M. "Effect of SDS concentration on the thermal property and performance of low pressure active reverse osmosis (LP-ARO) membrane for brackish and seawater desalination", Journal of Applied Science and Agriculture, 10(5), pp. 40-46, 2015. [online] Available at: http://www.aensiweb. com/old/jasa/rjfh/2015/Special1\%202015/40-46.pdf [Accessed: 05 January 2019]

[11] Fadilah, N. I. M., Hassan, A. R. "Asymmetric PVDF ultrafiltration (UF) membranes: effect of additives and surfactants", International Journal of Chemical and Environmental Engineering, 5(6), pp. 336-345, 2014.

[12] Fadilah, N. I. M., Hassan, A. R. "Preparation, Characterization and Performance Studies of Active PVDF Ultrafiltration-Surfactants Membranes Containing PVP as Additive", Advanced Materials Research, 1134, pp. 44-49, 2016.

https://doi.org/10.4028/www.scientific.net/AMR.1134.44

[13] Ghaemi, N., Madaeni, S. S., Alizadeh, A., Daraei, P., Vatanpour, V., Falsafi, M. "Fabrication of cellulose acetate/sodium dodecyl sulfate nanofiltration membrane: characterization and performance in rejection of pesticides", Desalination, 290, pp. 99-106, 2012.

https://doi.org/10.1016/j.desal.2012.01.013

[14] Zainal, S. H., Hassan, A. R., Isa, M. H. M. "The effect of polymer concentration and surfactant types on nanofiltration-surfactant membrane for textile wastewater", Malaysian Journal of Analytical Sciences, 20(6), pp. 1524-1529, 2016.

https://doi.org/10.17576/mjas-2016-2006-34

[15] Mulijani, S., Budianto, E., Hikam, M. "Formation and Characterization of Asymetric Nanofiltration Membrane: Effect of Temperature and Surfactant as a Template", ASEAN Journal on Science and Technology for Development, 27(1), pp. 21-29, 2010. [online] Available at: https://www.researchgate.net/publication/267214051 [Accessed: 05 January 2019]

[16] Saedi, S., Madaeni, S. S., Shamsabadi, A. A., Mottaghi, F. "The effect of surfactants on the structure and performance of PES membrane for separation of carbon dioxide from methane", Separation and Purification Technology, 99, pp. 104-119, 2012. https://doi.org/10.1016/j.seppur.2012.08.028

[17] Hassan, A. R., Safari, N. H. M., Rozali, S., Juahir, H., Kamarudin, M. K. A. "Effect of cetyle trimethyl ammonium bromide (CTAB) surfactant on nanofiltration membrane for dye removal", Malaysian Journal of Applied Sciences, 2(2), pp. 29-36, 2017. [online] Available at: https://journal.unisza.edu.my/myjas/index. php/myjas/article/view/89/36 [Accessed: 05 January 2019]

[18] Hassan, A. R., Sharifuddin, S. S., Isa, M. H. M., Yusra, A. F. I. "Assessment the performance and morphological structures of asymmetric PES/Surfactant membranes for nanofiltration of dyes wastewater", Journal of Fundamental and Applied Sciences, 9(2S), pp. 137-146, 2017. https://doi.org/10.4314/jfas.v9i2s.10

[19] Moochani, M., Moghadassi, A., Hosseini, S. M., Bagheripour, E., Parvizian, F. "Fabrication of novel polyethersulfone based nanofiltration membrane by embedding polyaniline-co-graphene oxide nanoplates", Korean Journal of Chemical Engineering, 33(9), pp. 2674-2683, 2016.

https://doi.org/10.1007/s11814-016-0132-4

[20] Hassan, A. R., Rozali, S., Safari, N. H. M., Besar, B. H. "The roles of polyethersulfone and polyethylene glycol additive on nanofiltration of dyes and membrane morphologies", Environmental Engineering Research, 23(3), pp. 316-322, 2018. https://doi.org/10.4491/eer.2018.023

[21] Madaeni, S. S., Arast, N., Rahimpour, F., Arast, Y. "Fabrication optimization of acrylonitrile butadiene styrene (ABS)/ polyvinylpyrrolidone (PVP) nanofiltration membrane using response surface methodology", Desalination, 280(1-3), pp. 305-312, 2011. https://doi.org/10.1016/j.desal.2011.07.020

[22] Ali, N. S. M., Hassan, A. R. "The effect of cationic and non ionic surfactant on molecular orientation and performance of low pressure reverse osmosis membrane for brackish water desalination", International Journal of Chemical and Environmental Engineering, 6(3), pp. 131-136, 2015.

[23] Mansourpanah, Y., Alizadeh, K., Madaeni, S. S., Rahimpour, A., Afarani, H. S. "Using different surfactants for changing the properties of poly (piperazineamide) TFC nanofiltration membranes", Desalination, 271(1-3), pp. 169-177, 2011. https://doi.org/10.1016/j.desal.2010.12.026

[24] Hassan, A. R., Munaim, M. S. A. "Fabrication and characterization of integrally skinned oriented highly selective charged asymmetric low pressure poly (ether sulfone) membranes for nanofiltration", Journal of Chemical Technology and Biotechnology, 87(4), pp. 559-569, 2012.

https://doi.org/10.1002/jctb.2751

[25] Ali, N. S. M., Hassan, A. R. "The effect of CTAB and SDS surfactant on the morphology and performance of low pressure active reverse osmosis membrane", Malaysian Journal of Analytical Sciences, 20(3), pp. 510-516, 2016. https://doi.org/10.17576/mjas-2016-2003-07

[26] Safari, N. H. M., Hassan, A. R., Takwa, C. W. I. C. W., Rozali, S. "Deduction of surfactants effect on performance, morphology, thermal and molecular properties of polymeric polyvinylidene fluoride (PVDF) based ultrafiltration membrane", Periodica Polytechnica Chemical Engineering, 63(1), pp. 27-35, 2019. https://doi.org/10.3311/PPch.12423

[27] Karimi, S., Firouzfar, E., Khoshchehreh, M. R. "Assessment of gas separation properties and $\mathrm{CO} 2$ plasticization of polysulfone/ polyethylene glycol membranes", Journal of Petroleum Science and Engineering, 173, pp. 13-19, 2019. https://doi.org/10.1016/j.petrol.2018.10.012

[28] Viana, R. B., da Silva, A. B. F., Pimentel, A. S. "Infrared spectroscopy of anionic, cationic, and zwitterionic surfactants", Advances in Physical Chemistry, 2012, ID: 903272, 2012. https://doi.org/10.1155/2012/903272

[29] Dumbrava, A., Berger, D., Prodan, G., Matei, C., Moscalu, F., Diacon, A. "The influence of Triton X-100 surfactant on the morphology and properties of zinc sulfide nanoparticles, with applications in azo dyes degradation", Materials Chemistry and Physics, 193, pp. 316-328, 2017. https://doi.org/10.1016/j.matchemphys.2017.02.040 